\title{
Front Matter: Volume 9960
}

, "Front Matter: Volume 9960," Proc. SPIE 9960, Interferometry XVIII, 996001 (28 August 2016); doi: 10.1117/12.2253965

EDent: SPIE Optical Engineering + Applications, 2016, San Diego, California, United States 


\section{PROCEEDINGS OF SPIE}

\section{Interferometry XVIII}

Katherine Creath

Jan Burke

Armando Albertazzi Gonçalves Jr.

Editors

30 August - 1 September 2016

San Diego, California, United States

Sponsored and Published by

SPIE 
The papers in this volume were part of the technical conference cited on the cover and title page. Papers were selected and subject to review by the editors and conference program committee. Some conference presentations may not be available for publication. Additional papers and presentation recordings may be available online in the SPIE Digital Library at SPIEDigitallibrary.org.

The papers reflect the work and thoughts of the authors and are published herein as submitted. The publisher is not responsible for the validity of the information or for any outcomes resulting from reliance thereon.

Please use the following format to cite material from this book:

Author(s), "Title of Paper," in Interferometry XVIII, edited by Katherine Creath, Jan Burke, Armando Albertazzi Gonçalves Jr., Proceedings of SPIE Vol. 9960 (SPIE, Bellingham, WA, 2016) Six-digit Article CID Number.

ISSN: 0277-786X

ISSN: 1996-756X (electronic)

ISBN: 9781510603110

ISBN: 9781510603127 (electronic)

Published by

SPIE

P.O. Box 10, Bellingham, Washington 98227-0010 USA

Telephone +1 3606763290 (Pacific Time) · Fax +1 3606471445

SPIE.org

Copyright (C) 2016, Society of Photo-Optical Instrumentation Engineers.

Copying of material in this book for internal or personal use, or for the internal or personal use of specific clients, beyond the fair use provisions granted by the U.S. Copyright Law is authorized by SPIE subject to payment of copying fees. The Transactional Reporting Service base fee for this volume is $\$ 18.00$ per article (or portion thereof), which should be paid directly to the Copyright Clearance Center (CCC), 222 Rosewood Drive, Danvers, MA 01923. Payment may also be made electronically through CCC Online at copyright.com. Other copying for republication, resale, advertising or promotion, or any form of systematic or multiple reproduction of any material in this book is prohibited except with permission in writing from the publisher. The CCC fee code is 0277-786X/16/\$18.00.

Printed in the United States of America.

Publication of record for individual papers is online in the SPIE Digital Library.

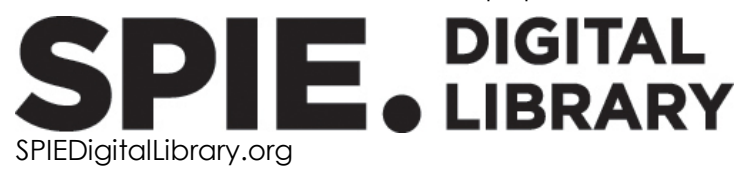

Paper Numbering: Proceedings of SPIE follow an e-First publication model, with papers published first online and then in print. Papers are published as they are submitted and meet publication criteria. A unique citation identifier (CID) number is assigned to each article at the time of the first publication. Utilization of CIDs allows articles to be fully citable as soon as they are published online, and connects the same identifier to all online, print, and electronic versions of the publication. SPIE uses a six-digit CID article numbering system in which:

- The first four digits correspond to the SPIE volume number.

- The last two digits indicate publication order within the volume using a Base 36 numbering system employing both numerals and letters. These two-number sets start with 00, 01, 02, 03, 04, $05,06,07,08,09,0 A, 0 B \ldots$.. 0Z, followed by 10-1Z, 20-2Z, etc.

The CID Number appears on each page of the manuscript. The complete citation is used on the first page, and an abbreviated version on subsequent pages. 


\title{
Contents
}

\author{
vii Authors \\ ix Conference Committee \\ xiii Introduction
}

\section{OCT AND QUANTITATIVE PHASE}

996002 Real time parallel phase shift orthogonal polarization interference microscopy (Invited Paper) [9960-1]

996003 Non-contact investigation of the corneal biomechanics with air-puff swept source optical coherence tomography [9960-4]

WHITE LIGHT AND MICROSCOPY TECHNIQUES

996004 Are those bugs reflective? non-destructive biofilm imaging with white light interferometry (Invited Paper) [9960-6]

996005 Applications of model-based transparent surface films analysis using coherence scanning interferometry [9960-7]

996006 Reduction of batwing effect in white light interferometry for measurement of patterned sapphire substrates (PSS) wafer [9960-8]

\section{AEROSPACE APPLICATIONS}

996007 An overview of interferometric metrology and NDT techniques and applications for the aerospace industry (Invited Paper) [9960-9]

CHANDRA S. VIKRAM ADDRESS

996008 Is holography ready for yet another life? or make holography great again [9960-12]

OPTICAL ENGINEERING PLENARY SESSION

996009 The advanced LIGO detectors in the era of first discoveries (Plenary Paper) [9960-200] 
9960 OA Recent advances in phase shifted time averaging and stroboscopic interferometry (Invited Paper) [9960-13]

9960 OB Improved adjoin-list for quality-guided phase unwrapping based on red-black trees [9960-14]

9960 0C Dual-phase-shift schemes for internal-reflection noise reduction in a Fizeau interferometer [9960-15]

9960 OD Single and two-shot quantitative phase imaging using Hilbert-Huang Transform based fringe pattern analysis [9960-16]

\section{ON THE FRINGE}

9960 OE Nano particle and defect defection: physical limit of state-of-the-art systems and novel measurement technique to improve upon this detection limit (Invited Paper) [9960-17]

$9960 \mathrm{OF}$ Subwavelength metrology of Al wire grating employing finite difference time domain method and Mueller matrix polarimeter [9960-18]

9960 OG A network of heterodyne laser interferometers for monitoring and control of large ringlasers [9960-19]

$9960 \mathrm{OH}$ Effect of beam quality on tilt measurement using cyclic interferometer [9960-20]

\section{CALIBRATION TECHNIQUES}

9960 ol The concept and implementation of smooth generic camera calibration (Invited Paper) [9960-21]

9960 0J Moire interferometry patterns for rotational alignment of structures [9960-22]

9960 OK Motion artifact reduction using hybrid Fourier transform with phase-shifting methods [9960-23]

$9960 \mathrm{OL}$ A non-linear piezoelectric actuator calibration using $\mathrm{N}$-dimensional Lissajous figure [9960-24]

\section{DEFLECTOMETRY AND FREEFORM METROLOGY}

9960 OM Testing the performance of freeform LED optics by gradient based measurement [9960-25]

$9960 \mathrm{ON}$ Determination of the paraxial focal length of strong focusing lenses using Zernike polynomials in simulation and measurement [9960-27]

996000 Line scanning deflectometry using a laser pico projector [9960-28] 
9960 OP Optical metrology in the conflict between desire and reality (Invited Paper) [9960-30]

\section{DIGITAL HOLOGRAPHY AND SPECKLE}

$99600 Q \quad$ Digital holographic interferometry for characterizing deformable mirrors in aero-optics [9960-31]

9960 OR Digital holographic interferometry based on hexa-lateral derivative and reflection holography [9960-32]

9960 OS Two dimensional deformation vector analysis using speckle interferometry with same sensitivity in three directions [9960-33]

9960 OT Single beam off-axis digital holography of laser driven jet using ring cavity [9960-34]

\section{GRATING AND FIBER SENSORS}

9960 OU Dynamic high pressure measurements using a Fiber Bragg Grating probe and an arrayed waveguide grating spectrometer [9960-35]

9960 OV Adaptive grating interferometric sensor for NDE metrology in high energy electromagnetic environment [9960-36]

9960 0W Mechanical design optimization of a single-axis MOEMS accelerometer based on a grating interferometry cavity for ultrahigh sensitivity [9960-38]

9960 0X The analysis of temperature effect and temperature compensation of MOEMS accelerometer based on a grating interferometric cavity [9960-39]

\section{POSTER SESSION}

$99600 Z$ Optimizing multiplexing scheme in interferometric microscopy [9960-5]

996010 Improvement of spectrally resolved interferometry without direction ambiguity and dead zone [9960-40]

996011 Two-step phase shiffing interferometry technique for evaluation of fatigue process zone parameters in notched specimens [9960-42]

996012 Spectral resolution measurement technique for Czerny-Turner spectrometers based on spectral interferometry [9960-43]

996013 A method for the analysis and data reduction from Hartmann and Shack-Hartmann tests [9960-44]

996014 Polarization characterization of liquid-crystal variable retarders [9960-45] 
996015 Analysis of a shearography device using a Wollaston prism and polarization phase shifting [9960-46]

996016 Optical frequency comb profilometry based on a single-pixel phase imaging [9960-47]

996017 Testing optical surfaces using two-frame phase-shifting interferometry [9960-50]

996018 Orthogonal polynomials and global optimization based demodulation of two-shot fringe patterns [9960-53]

996019 Self-mixing grating interferometer: theoretical analysis and experimental observations [9960-56] 


\section{Authors}

Numbers in the index correspond to the last two digits of the six-digit citation identifier (CID) article numbering system used in Proceedings of SPIE. The first four digits reflect the volume number. Base 36 numbering is employed for the last two digits and indicates the order of articles within the volume. Numbers start with 00, 01, 02, 03, 04, 05, 06, 07, 08, 09, OA, OB...0Z, followed by 10-12, 20-2Z, etc.

\author{
Abdulhalim, I., 02 \\ Addleman, R. Shane, 04 \\ Adhikari, Achyut, OF \\ Albertazzi, A. G., OL, 15 \\ Altintepe, Kadir, OV \\ Arai, Y., OS \\ Asundi, Anand, OF \\ Bai, Jian, OW, OX \\ Barbarin, Y., OU \\ Beghi, Alessandro, OG \\ Belfi, Jacopo, 0G \\ Benedet, M. E., 15 \\ Beverini, Nicolò, OG \\ Binkele, Tobias, $0 \mathrm{~N}$ \\ Bodnar, Michael, OV \\ Bonheyo, George, 04 \\ Bosi, Filippo, 0G \\ Brann, Michelle, 04 \\ Bruce, Neil C., 14 \\ Carelli, Giorgio, OG \\ Chang, Yi-Wei, 06 \\ Chen, Guanghua, OT \\ Chien, Shih-Che, 00 \\ Contreras Martínez, Ramiro, 12 \\ Cruz-Santos, William, OB \\ Cuccato, Davide, OG \\ Desse, Jean Michel, OR \\ Dev, Kapil, OF \\ Di Virgilio, Angela, OG \\ Donazzan, Alberto, 0G \\ Dovgalenko, George, OV \\ Dresel, Thomas, 05 \\ Fantin, A. V., OL, 15 \\ Fay, Martin F., 05 \\ Ferreira, Carlos, OD \\ Fleischmann, Friedrich, OM, ON \\ Furlong, Cosme, $0 Q$ \\ Ganesan, A. R., $\mathrm{OH}$ \\ Gantes Nuñez, Fco. Javier, 13 \\ García-Monreal, Javier, OD \\ Garduño Mejía, Jesús, 12 \\ Georges, Marc P., 07 \\ Grulkowski, Ireneusz, 03 \\ Guo, Dongmei, 19 \\ Han, Dandan, OW, OX \\ Han, Jae-Ho, $\mathrm{OZ}$ \\ Hao, Hui, 19 \\ Harding, Kevin, 0J \\ Hayasaki, Yoshio, 16
}

Heidari, Esmaeil, OJ

Henning, Thomas, OM, ON

Hess, Cecil F., OQ

Hibino, Kenichi, OC

Hilbig, David, OM, ON

Jaferzadeh, Keyvan, $0 Z$

Jiao, Xufen, OW, OX

Joenathan, $\mathrm{C} ., \mathrm{OH}$

Joo, Ki-Nam, 10

Józwik, Michał, OA

Kaluzny, Bartlomiej, 03

Karnowski, Karol, 03

Kmet, Arkady B., 11

Koek, Wouter D., OE

Kumagai, Toshiki, OC

Languy, Fabian, 07

Larimer, Curtis, 04

Lefrançois, A., OU

Li, Beiwen, OK

$\mathrm{Li}$, Jun, OT

$\mathrm{Li}, \mathrm{Mu}, \mathrm{OT}$

Liang, Chao-Wen, 00

Liu, Jun, OT

Liu, Shengchun, 17, 18

Liu, Shouxian, OT

Liu, Ziping, OK

López-García, Lourdes, OB

López-Téllez, Juan M., 14

Lou, Shuqi, OW, OX

Lu, Qianbo, OW, OX

LUC, J., OU

Luo, Zhenxiong, OT

Maccioni, Enrico, OG

Maczynska, Ewa, 03

Magne, S., OU

Makhtar, Nabila, 16

Malacara Hernández, Daniel, 13

Malacara Hernández, Zacarías, 13

Micó, Vicente, OD

Mizutani, Yasuhiro, 16

Montes, Iván, 14

Muravsky, Leonid I., 11

Nagaike, Yasunari, OC

Naletto, Giampiero, $0 \mathrm{G}$

Olchewski, François, OR

Ortolan, Antonello, OG

Osmont, A., OU

Ostash, Orest P., 11

Osten, W., OP 
Pak, Alexey, 01

Patorski, Krzysztof, OD

Pelizzo, Maria G., OG

Pham, Quang Duc, 16

Picart, Pascal, OR, 11

Porzio, Alberto, OG

Pretheesh Kumar, V. C., $\mathrm{OH}$

Prokop, Joseph, OV

Razavi, Payam, $0 Q$

Redondo-Galvan, Arturo, OB

Román Moreno, Carlos J., 12

Rosete Aguilar, Martha, 12

Rueda-Paz, Juvenal, OB

Sadeghian, Hamed, OE

Safrani, A., 02

Sanchez, E., 15

Santagata, Rosa, OG

Sharif, Farnaz, $\mathrm{OZ}$

Sigg, Daniel, 09

Simonelli, Andreino, OG

Sinatti, F., OU

Sluzewski, Lukasz, OD

Somasundaram, U., $\mathrm{OH}$

Stasyshyn, Ihor V., 11

Styk, Adam, OA

Suter, Jonathan D., 04

Tapilouw, Abraham Mario, 06

Tartaglia, Angelo, OG

Tayebi, Behnam, $\mathrm{OZ}$

Thizy, Cédric, 07

Tian, Chao, 17, 18

Trolinger, James D., 08, 0Q

Trusiak, Maciej, OD

van Zwet, Erwin J., OE

Vandenrijt, Jean-François, 07

Veiga, C. L. N., OL

Viotti, M. R., OL

Voronyak, Taras I., 11

Wang, Hau-Wei, 06

Wang, Kaiwei, OW

Wang, Ming, 19

Willemann, D. P., 15

Woirin, K., OU

Wojtkowski, Maciej, 03

Yang, Guoguang, OW, OX

Yu, Long-Yo, 06

Yun, Young $\mathrm{Ho}, 10$

Zhan, Hao-Xun, 00

Zhang, Song, OK 


\title{
Conference Committee
}

\author{
Program Track Chair
}

Katherine Creath, Optineering (United States) and The University of Arizona (United States)

Conference Chairs

Katherine Creath, Optineering (United States) and The University of Arizona (United States)

Jan Burke, Fraunhofer-Institut für Optronik, Systemtechnik und Bildauswertung (Germany)

Armando Albertazzi Gonçalves Jr., Universidade Federal de Santa Catarina (Brazil)

Conference Program Committee

Astrid Aksnes, Norwegian University of Science and Technology (Norway)

Anand Krishna Asundi, Nanyang Technological University (Singapore) Peter J. de Groot, Zygo Corporation (United States)

Nicholas Devaney, National University of Ireland, Galway (Ireland) Konstantinos Falaggis, Warsaw University of Technology (Poland) Ángel M. Fernández Doval, Universidade de Vigo (Spain) Pietro Ferraro, Istituto di Scienze applicata e Sistemi Intelligenti (Italy) Cosme Furlong, Worcester Polytechnic Institute (United States) Marc P. Georges, Université de Liège (Belgium) Christophe Gorecki, FEMTO-ST (France) Ulf Griesmann, National Institute of Standards and Technology (United States)

Erwin Hack, EMPA (Switzerland)

Tobias Haist, Universität Stuttgart (Germany)

Sen Han, University of Shanghai for Science and Technology (China) Chao-Wen Liang, National Central University (Taiwan)

Klaus Mantel, Max-Planck-Institut für die Physik des Lichts (Germany) Amalia Martínez, Center de Investigaciones en Óptica, A.C. (Mexico) Michael B. North Morris, 4D Technology Corporation (United States) Erik Novak, 4D Technology Corporation (United States) Jirí Novák, Czech Technical University in Prague (Czech Republic) Yukitoshi Otani, Utsunomiya University (Japan) Pascal Picart, Université du Maine (France) Joanna Schmit, Bruker Nano Surfaces Division (United States) Adam R. Styk, Warsaw University of Technology (Poland) James D. Trolinger, MetroLaser, Inc. (United States) Song Zhang, Purdue University (United States) 


\section{Session Chairs}

OCT and Quantitative Phase

Katherine Creath, Optineering (United States) and The University of Arizona (United States)

White Light and Microscopy Techniques

Ibrahim Abdulhalim, Ben-Gurion University of the Negev (Israel)

Aerospace Applications

James D. Trolinger, MetroLaser, Inc. (United States)

Chandra S. Vikram Address

Katherine Creath, Optineering (United States) and The University of Arizona (United States)

Fringe Analysis Techniques

Joanna Schmit, 4D Technology Corporation (United States)

On the Fringe

Marc P. Georges, Centre Spatial de Liège (Belgium)

Calibration Techniques

Chao-Wen Liang, National Central University (Taiwan)

Deflectometry and Freeform Metrology

Jan Burke, Fraunhofer-Institut für Optronik, Systemtechnik und Bildauswertung (Germany)

Discussion of Future Interferometry and Metrology Conferences

Katherine Creath, Optineering (United States) and The University of Arizona (United States)

Jan Burke, Fraunhofer-Institut für Optronik, Systemtechnik und Bildauswertung (Germany)

Armando Albertazzi Gonçalves Jr., Universidade Federal de Santa Catarina (Brazil)

Fringe Art Awards Voting and Presentation

Katherine Creath, Optineering (United States) and The University of Arizona (United States)

Joanna Schmit, 4D Technology Corporation (United States)

Future of Optical Metrology

Armando Albertazzi Gonçalves Jr., Universidade Federal de Santa Catarina (Brazil) 
Digital Holography and Speckle

Armando Albertazzi Gonçalves Jr., Universidade Federal de Santa Catarina (Brazil)

Grating and Fiber Sensors

Pascal Picart, Université du Maine (France)

Proc. of SPIE Vol. $9960996001-11$

Downloaded From: https://www.spiedigitallibrary.org/conference-proceedings-of-spie on 26 Apr 2023 Terms of Use: https://www.spiedigitallibrary.org/terms-of-use 
Proc. of SPIE Vol. $9960996001-12$

Downloaded From: https://www.spiedigitallibrary.org/conference-proceedings-of-spie on 26 Apr 2023 Terms of Use: https://www.spiedigitallibrary.org/terms-of-use 


\section{Introduction}

This is the eighteenth installment of the Interferometry conference - it has not always taken place in the current bi-annual format, so its beginnings reach back to the 1980s. For those of you who are old enough to remember, take a moment to re-play the reel of progress since; for those who are not, take a look at a yellow book with a three-digit number or download a scanned typewriter manuscript, marvel at the clumsy ways things were done then, and realize that the reason we are looking so much smarter today is because we are. All the mistakes we make (and share), all this apparent erring and bumbling leads to knowledge of how we might have begun in the first place - just one case and success story in point: the Laser Interferometer Gravitational-Wave Observatory. As such, we understand this book to be another chapter in the endless chronicle of trial, error, and improvement.

A trial with this conference is that this time we do not have the two subconferences "Techniques and Analysis" and "Applications" but rather a combination of the two. We have had fewer contributions than usual; this may have to do with the late date for the meeting, which for many has been after the summer break - but possibly also with confusion as to what the new format means and where to place contributions. As at the time of writing, we are looking forward to the discussion with you about the future and format of the conference.

There have been unusually many withdrawals this time, due to various reasons, ranging from visa issues to clearance for publication. The Chairs would like to encourage potential authors to start such foreseeable processes early - being focused on the scientific results, it is easy to forget about the more mundane things around attending a conference. Also, from experience, it is a good idea to have at least part of the results already "in the bag" - there is not one among us who has never experienced the last-minute rush that comes with trying to meet a deadline that involves the rest of the experimental program besides the writing process.

Having said that, we do applaud the authors who decided not to rush things along just for the sake of the deadline, and we are very happy with the quality of the material we did receive. As usual, it has gone through a peer-review process to ensure we all get a conference volume that will be useful as a reference for many years. The featured authors, from 18 countries, have brought inspiring papers to this forum, which we are very pleased to present in this book. It contains 44 papers presented at the SPIE's $61^{\text {st }}$ Annual Meeting in San Diego on August 30 -September 1, 2016. Thirty-two of these papers were presented orally. 
When thinking of interferometry, the first thing coming to mind is of course the phase of wavefronts, as used so beautifully in non-destructive testing and holography. One feature of this conference is the Chandra S. Vikram Address, a look upon the past (and future) of holography, given by the 2016 winner of the Vikram Award, James D. Trolinger. We plan to continue highlighting winners of this award at future conferences.

Of course, the wavefront measurement can also gainfully be coupled with other properties of light, such as polarization and coherence, whose manipulation and use are featured in a number of exciting applications. We have mentioned LIGO above, and part of this year's Plenary program is an overview of the progress and observations made with the advanced version of the instrument, which from the outside looks like just a giant Michelson interferometer, but requires a very large number of tweaks to achieve a level of sensitivity that even Einstein could not imagine.

While LIGO is surely the cover story of this year, we have a number of other contributions on pushing the boundaries of metrology and detection methods, as well as further progress reports on the timeless topic of advanced fringe generation and analysis. Calibration methods are the foundation of quantitative metrology, and this topic is also covered by several authors from different areas of research. A useful complement to interferometry is deflectometry, using geometrical optics for measurements with very high dynamic range, and some practical applications of the technique are featured in this volume.

Further classical topics such as speckle interferometry and digital holography are also represented - just like any other topic, they started as tentative new ideas several decades ago and are now serving as an established base for many initially unusual ideas of today. Finally, we have a section on multiple-beam interferometers, viz., very sensitive grating sensors, whose principles are also well known and whose use continues to spread.

The range of topics presented reflects the versatility and ubiquity of optical metrology like the photon itself, it pervades our world, and its importance is most easily recognized in its absence.

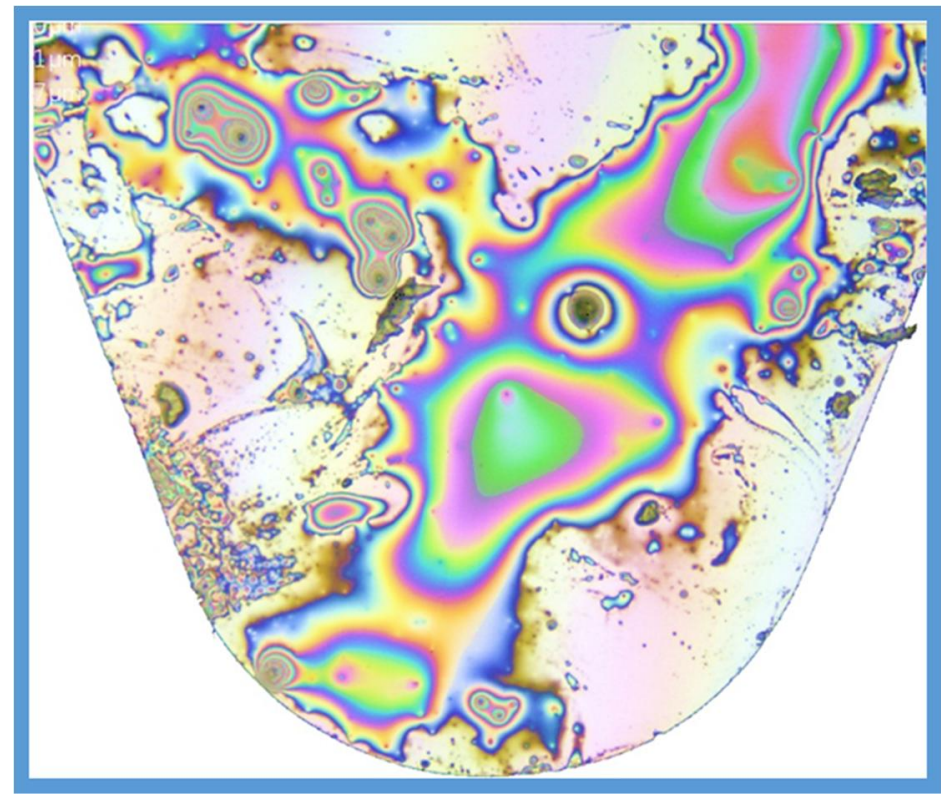


During our last conference in 2014 , we had once more a very lively and fun Fringe Art competition with several rounds of voting, choosing our favorite fringe patterns from those brought along by attendees. The origin of phenomena submitted to the Fringe Art Competition spanned the range from mouse neurons and ear drum vibrations to more common objects such as vibrating cantilevers, moiré, diffraction patterns, and waves caused by wind on San Diego harbor and Coronado beach.

The image ultimately selected as the favorite was submitted by Dr. Jake Beverage, then at Zygo Corp., Middlefield, CT USA (now with Arizona Optical Systems, Tucson, AZ USA). The image is of a cutting tool covered with a thin oil film, viewed through the ZYGO Nexview ${ }^{\mathrm{TM}}$ interference microscope with color imaging. The imaging area is $0.9 \mathrm{~mm} \times 0.9 \mathrm{~mm}$. In the image you can see both the faint interference fringes as well as the thin film interference.

Let us close with a sincere thank-you to SPIE, the program committee, the authors, and everyone attending this eighteenth Interferometry conference. As we have said last time, metrology never goes out of style, and a few things deemed too hard or even impossible even two years ago have been demonstrated now, encouraging further demands for the (almost) impossible (again, who of us has not experienced this?!). Besides the incremental broadening of scopes and sharpening of sensitivities, there were also "the usual surprises", i.e. innovative uses opening up new ways of thinking. We are very pleased that SPIE continues to support and provide this forum for us.

Until next time!

Katherine Creath

Jan Burke

Armando Albertazzi Gonçalves Jr. 
Proc. of SPIE Vol. $9960996001-16$

Downloaded From: https://www.spiedigitallibrary.org/conference-proceedings-of-spie on 26 Apr 2023 Terms of Use: https://www.spiedigitallibrary.org/terms-of-use 